\title{
Identification of Long-range Transported Polycyclic Aromatic Hydrocarbons in Snow at Mt. Tateyama, Japan
}

\author{
Kazuichi Hayakawa $^{1 *}$, Ning Tang ${ }^{1,2}$, Edward G. Nagato ${ }^{1}$, Akira Toriba ${ }^{2}$, Kazuma Aoki $^{3}$ \\ ${ }^{1}$ Institute of Nature and Environmental Technology, Kanazawa University, Kakuma-machi, Kanazawa, 920-1192 Japan \\ ${ }^{2}$ Institute of Medical, Pharmaceutical and Health Sciences, Kanazawa University, Kakuma-machi, Kanazawa, $920-1192$ \\ Japan \\ ${ }^{3}$ Faculty of Science, University of Toyama, Toyama-shi, Toyama 930-8555, Japan
}

\begin{abstract}
Snow layers, L-I to -III, collected from the wall of a snow pit at Murododaira on Mt. Tateyama, Japan, were melted and filtered into soluble (S) and particulate $(\mathrm{P})$ fractions by a glass filter (pore size: $0.5 \mu \mathrm{m}$ ). The total concentration of the polycyclic aromatic hydrocarbons (PAHs) was highest in L-I. In this layer, PAHs with 5-6 rings, which exist mainly in particulate matter (PM) in the atmosphere, were almost completely in the P-fraction. PAHs with 4 rings, which exist in both the particle and the gas phase in the atmosphere, exhibited higher or equal concentrations in the S-fraction. Finally, non-sea salt $\mathrm{SO}_{4}{ }^{2-}$, which exists as sulfur oxides in the atmosphere, was filtered into the S-fraction. The air mass for L-I, traced via back trajectory, passed through northeastern and central China. These results suggest that PAHs transported from China to Japan precipitated in snow at Mt. Tateyama. In the melted snow, PM-associated PAHs were primarily in the P-fraction, but lower molecular-weight PAHs were partly in the S-fraction. Gas-phase PAHs were also found in the Sfraction. Furthermore, the high concentration of non-sea salt $\mathrm{Ca}^{2+}$ in the S-fraction of L-I implies the presence of Asian Dust.
\end{abstract}

Keywords: Snow; Long-range transported particulate matter; Polycyclic aromatic hydrocarbon; Inorganic ion; Mt. Tateyama.

\section{INTRODUCTION}

Asian Dust (yellow sand) and sulfates are long-range transported from the Asian continent to Japan over the Sea of Japan (Iwasaka et al., 1988; Nishikawa et al., 1991). Recently, we collected total suspended particulate matters (TSP) at Wajima Atmospheric Monitoring Site (WAMS), Kanazawa University, on the Noto Peninsula, Japan, downstream of the westerlies from the Asian continent and analyzed polycyclic aromatic hydrocarbons (PAHs) and nitropolycyclic aromatic hydrocarbons (NPAHs) in the TSP. Atmospheric PAH and NPAH concentrations at WAMS increased in winter season every year. Back trajectory and chemical compositional analyses supported that the increase of the PAH concentrations was caused by long-range transported particulate matters (PM) emitted from combustion of fossil fuels and/or biomass in China (Yang et al., 2007; Hayakawa et al., 2011; Tang et al., 2015). As fine PM with

\footnotetext{
* Corresponding author.

Tel.: +81-76-234-4942

E-mail address: hayakawa@p.kanazawa-u.ac.jp
}

a diameter of not more than $2.5 \mu \mathrm{m}\left(\mathrm{PM}_{2.5}\right)$ is carcinogenic to human (IARC, 2013), the effect of long-range transported PM-associated PAHs on human health has attracted much attention.

Mt. Tateyama (3,015 $\mathrm{m}$ above sea level), one of the highest mountains on the west coast of Honshu, Japan, is about $110 \mathrm{~km}$ southeast of WAMS (Fig. 1). Murododaira, a flat area whose altitude is 2,450 $\mathrm{m}$ near the summit of Mt. Tateyama, is covered with deep snow every winter (Fig. 2), suggesting that snow in Mt. Tateyama could be useful for studying long-range transported atmospheric pollutants. Several pollutants such as Asian Dust and sulfur oxides in snow in this area were reported (Honoki et al., 2001; Osada et al., 2004; Watanabe et al., 2011a).

Thermal-optical analysis measures elemental and organic carbons in PM. However, this method is not specific for PM from combustion of organic matters. Moreover, PAHs with 5 rings and more exist in PM in the atmosphere, while PAHs having 4 rings or fewer exist in PM and/or gas phase (Araki et al., 2009). This suggests that the separate determination of PAHs in PM and the gas phase gives us valuable information concerning not only the long-range transport of combustion PM but also atmospheric behaviors of PAHs. Trace levels of PAHs can be quantified by several 


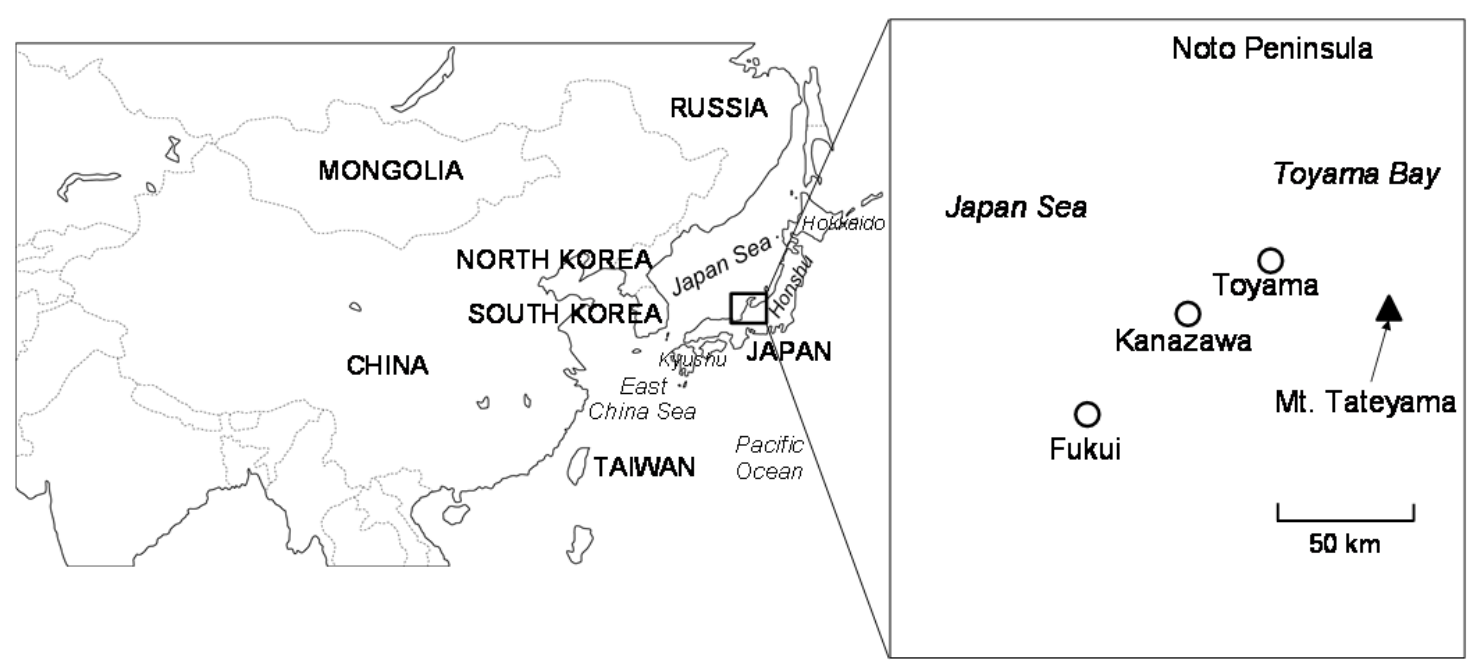

Fig. 1. Map of Mt. Tateyama in East Asia.

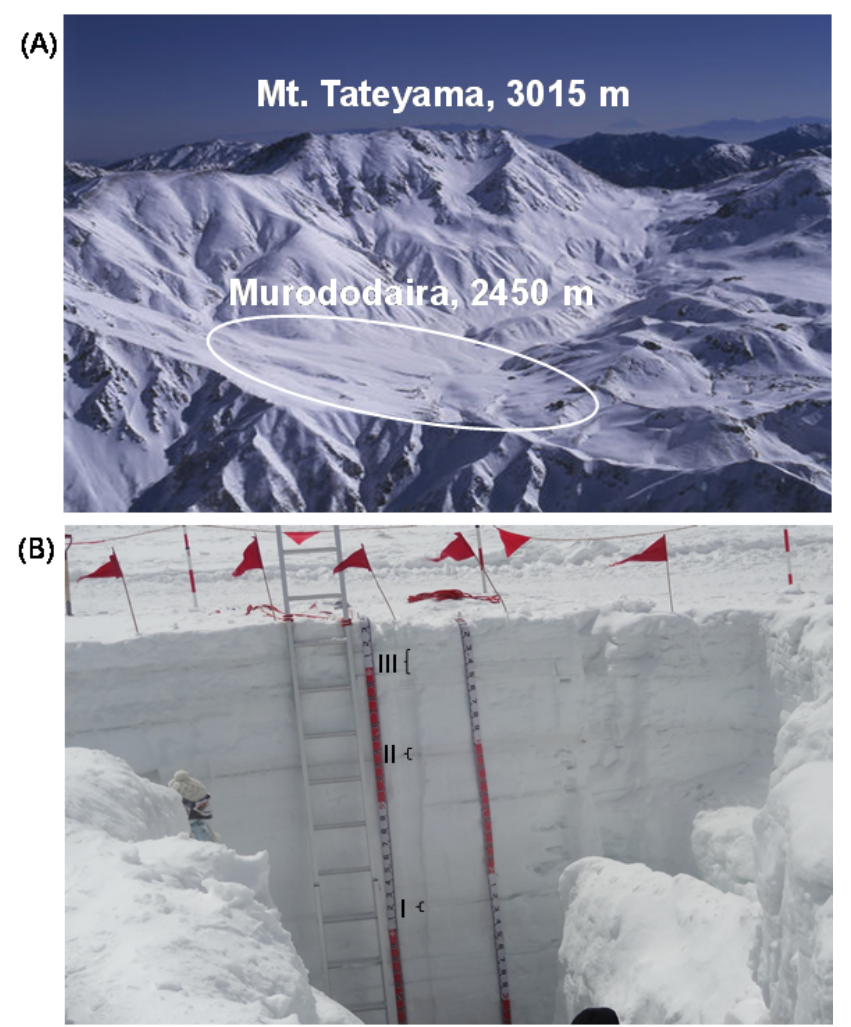

Fig. 2. (A) Murododaira and (B) the Snow Pit I, II and III are snow layers collected (Characteristics are described in Table 1).

methods including gas chromatography-mass spectrometry, liquid chromatography-mass spectrometry and highperformance liquid chromatography with fluorescence detection (HPLC-FLD) (Hayakawa et al., 2017). However, to the best of our knowledge, there is not any report concerning the distribution of PAHs in snow at Mt. Tateyama. In this report, the PAHs in snow were separated into PM and soluble fractions by filtration, and PAHs and inorganic ions were determined in the fractions by the combined use of HPLC-FLD and ion-chromatography (IC) to identify PM-associated PAHs in snow at Mt. Tateyama. By using results, the atmospheric behavior of PAHs and inorganic pollutants long-range transported over the Sea of Japan was discussed.

\section{METHODS}

\section{Sampling and Treatment}

The snow pit, $6.36 \mathrm{~m}$ deep, was dug at Murododaira on Mt. Tateyama in mid-April, 2015 (Fig. 2(B)). Snow blocks (each $2-3.5 \mathrm{~kg}$ ) were collected from three layers (L-I through -III from the ground) on the inside wall and stored in cooling boxes. After returned to the laboratory at Kanazawa University, they were melted in glass beakers at 
room temperature. The heights, colors, volumes and PM concentrations of the three samples are described in Table 1.

Each sample solution was filtered with a GC50 glass fiber filter (pore size: $0.5 \mu \mathrm{m}$, diameter: $47 \mathrm{~mm}$; Advantec, Tokyo, Japan) to obtain soluble (S) and particulate (P) fractions. An aliquot $(100 \mu \mathrm{L})$ of the filtrate (S-fraction) was injected into the IC to determine inorganic ions. The remaining filtrate was spiked with ethanol solution containing pyrene- $d_{10}\left(\right.$ Pyr- $\left.d_{10}\right)$ and benzo $[a]$ pyrene- $d_{12}\left(\mathrm{BaP}-d_{12}\right)$ as internal standards, and then the solution was passed through an Empore $\mathrm{C}_{18}$ disk (diameter: $47 \mathrm{~mm}$; 3M Series, Saint Paul, USA). PAHs adsorbed on the disk were eluted in dichloromethane. After evaporating the eluate, the precipitate was dissolved in $n$-hexane. The solution was treated with a Sep-Pak Silica Cartridge (6 cc; Waters, Milford, USA) and then PAHs were eluted with acetone/n-hexane. After evaporating the eluate, the precipitate was dissolved in ethanol. This solution was used for determining PAHs in the S-fraction. After spiking the same internal standards as for the filtrate, the precipitate on the glass filter was extracted with benzene/ethanol. The benzene solution (the P-fraction) was washed with alkaline and acidic solutions and water, successively. After the benzene solution was evaporated, the precipitate was dissolved in ethanol. This solution was used for determining PAHs in the P-fraction.

\section{Quantification of PAHs and Inorganic Ions}

An HPLC-FLD (LC-20 Series; Shimadzu, Kyoto, Japan) was used for determining fluoranthene (FR), pyrene (Pyr), benz $[a]$ anthracene (BaA), chrysene (Chr), benzo $[b]$ fluoranthene $(\mathrm{BbF})$, benzo $[k]$ fluoranthene $(\mathrm{BkF})$, benzo $[a]$ pyrene $(\mathrm{BaP}), \operatorname{dibenz}[a, h]$ anthracene (DBA), benzo[ghi]perylene (BghiPe) and indeno[1,2,3-cd]pyrene IDP). The analytical column was an Inertsil ODS-P (4.6 i.d. $\times$ $250 \mathrm{~mm}$; GL Sciences Inc., Tokyo, Japan) and the mobile phase was an acetonitrile/water mixture with a gradient mode. The flow rate of the mobile phase was $1 \mathrm{~mL} \mathrm{~min}{ }^{-1}$. The time program of FLD was set to detect at the optimum excitation and emission wavelengths for each PAH. Other conditions were the same as in our previous report (Tang et al., 2017). Inorganic ions were analyzed with a 761 Compact IC equipped with a conductivity detector (Metrohm Japan; Tokyo, Japan). Lithium $\left(\mathrm{Li}^{+}\right)$, sodium $\left(\mathrm{Na}^{+}\right)$, ammonium $\left(\mathrm{NH}_{4}^{+}\right)$, magnesium $\left(\mathrm{Mg}^{2+}\right)$ and calcium $\left(\mathrm{Ca}^{2+}\right)$ cations were determined with a Shodex IC YK-421 analytical column (4.0 i.d. $\times 250 \mathrm{~mm}$; Showa Denko, Toyko, Japan) with $5 \mathrm{mM}$ tartaric acid/1 $\mathrm{mM}$ dipicolin acid (1:1) as an eluent. Fluoride $\left(\mathrm{F}^{-}\right)$, chloride $\left(\mathrm{Cl}^{-}\right)$, nitrite $\left(\mathrm{NO}_{2}{ }^{-}\right)$, nitrate $\left(\mathrm{NO}_{3}{ }^{-}\right)$, bromate $\left(\mathrm{Br}^{-}\right)$, phosphate $\left(\mathrm{PO}_{4}{ }^{3-}\right)$ and sulfate
$\left(\mathrm{SO}_{4}{ }^{2-}\right)$ anions were determined with a SI-90 4E analytical column (4.0 i.d. $\times 250 \mathrm{~mm}$; Showa Denko, Toyko, Japan) with $1.8 \mathrm{mM} \mathrm{Na}_{2} \mathrm{CO}_{3} / 1.7 \mathrm{mM} \mathrm{NaHCO}_{3}(1: 1)$.

\section{Analyses}

Concentrations of non-sea-salt sulfate $\left(\mathrm{nsSSO}_{4}{ }^{2-}\right)$ and calcium $\left(\mathrm{nssCa}^{2+}\right)$ were calculated as follows:

$\mathrm{nsSSO}_{4}{ }^{2-}=\mathrm{SO}_{4}{ }^{2-}-\left(\mathrm{SO}_{4}{ }^{2-} / \mathrm{Na}^{+}\right)_{\text {seawater }} \times \mathrm{Na}^{+}$

$\mathrm{nssCa}^{2+}=\mathrm{Ca}^{2+}-\left(\mathrm{Ca}^{2+} / \mathrm{Na}^{+}\right)_{\text {seawater }} \times \mathrm{Na}^{+}$

where $\left(\mathrm{SO}_{4}{ }^{2-} / \mathrm{Na}^{+}\right)_{\text {seawater }}$ and $\left(\mathrm{Ca}^{2+} / \mathrm{Na}^{+}\right)_{\text {seawater }}$ are the concentration ratios (equivalent ratios) of $\mathrm{SO}_{4}{ }^{2-}$ to $\mathrm{Na}^{+}$ (0.12) and $\mathrm{Ca}^{2+}$ to $\mathrm{Na}^{+}(0.044)$ in seawater, respectively (Keene et al., 1986).

Mt. Tateyama weather, snowfall/depth, and snowcap data were obtained from the Toyama local meteorological office, Japan Meteorological Agency (http//www.jmanet.go.jp/toyama). 3-day back trajectories were calculated with NOAA HYSPLIT Trajectory Model provided by National Oceanic and Atmospheric Administration (https://ready.arl.noaa.gov/hypub-bin/trajtype.pl).

\section{RESULTS AND DISCUSSION}

\section{PM Concentration and Color}

Murododaira typically accumulates snow from early late October to late April and snow usually melts by summer. The colors of the bottom layer (L-I), the middle layer (L-II) and the top layer (L-III) were light black, light brown and white, respectively (Fig. 2(B)). The PM concentrations were $3.4,3.12$ and $1.94 \mathrm{mg} \mathrm{L}^{-1}$, respectively, and the fiber filters were black, black and grey, respectively. These results suggested that L-I and -II contain Asian Dust and/or combustion PM (Table 1).

\section{PAHs}

The concentrations of the 10 PAHs were highest in L-I (Table 2). The data in Tables 1 and 2, when taken together, suggest that L-I was most contaminated with dust and gas exhausted from combustion. In this layer, the PAHs distributed differently between the S- and P-fractions. The concentrations of the 4-ring PAHs (FR and Pyr) were higher in the S-faction than in the P-fraction. Concentrations of $\mathrm{BaA}$ and $\mathrm{Chr}$ were higher in the P-fraction but comparable to those in the S-fraction. More than $75.5 \%$ of the 5-ring PAHs (BbF, BkF, BaP and DBA) and most (more than 97\%) of the 6-ring PAHs (BghiPe and IDP) were in the P-fraction. This result showed that the percentage

Table 1. Snow Samples Collected from the Snow Pit.

\begin{tabular}{lllll}
\hline Layer & Height from ground $(\mathrm{m})^{\mathrm{a}}$ & Color $(\text { Snow/Filter })^{\mathrm{b}}$ & Volume $(\mathrm{L})$ & $\mathrm{PM}^{\left(\mathrm{mg} \mathrm{L}^{-1}\right)}$ \\
\hline III & $5.90-6.10$ & White/Gray & 2.95 & 1.94 \\
II & $5.33-5.39$ & Brown/Black & 3.12 & 3.12 \\
I & $4.13-4.20$ & Black/Black & 3.40 & 3.40 \\
\hline
\end{tabular}

\footnotetext{
${ }^{\mathrm{a}}$ Total depth of snow pit: $6 \mathrm{~m} 36 \mathrm{~cm}$.

${ }^{\mathrm{b}}$ Color of snow layer/color of glass filter.
} 
Table 2. Concentrations of PAHs in the Snow.

\begin{tabular}{llllllllllll}
\hline Layer & Fraction & FR & Pyr & BaA & Chr & BbF & BkF & BaP & DBA & BghiPe & IDP \\
\hline III & S & 2.63 & 2.39 & 2.49 & 1.59 & 1.15 & 0.34 & 0.30 & 0.01 & 0.01 & 0.01 \\
& P & 1.30 & 0.96 & 0.32 & 0.85 & 1.36 & 0.43 & 0.56 & 0.02 & 0.16 & 0.88 \\
& Total & 3.93 & 3.35 & 2.81 & 2.44 & 2.51 & 0.77 & 0.86 & 0.03 & 0.17 & 0.89 \\
II & S & 1.93 & 2.00 & 0.89 & 0.95 & 0.43 & 0.11 & 0.13 & 0.02 & 0.03 & 0.01 \\
& P & 0.60 & 0.42 & 0.12 & 0.28 & 0.40 & 0.11 & 0.18 & 0.01 & 0.02 & 0.27 \\
& Total & 2.53 & 2.42 & 1.01 & 1.23 & 0.83 & 0.22 & 0.31 & 0.03 & 0.15 & 0.28 \\
I & S & 39.0 & 19.5 & 2.01 & 10.4 & 3.03 & 0.98 & 1.51 & 0.01 & 0.03 & 0.01 \\
& P & 17.2 & 11.0 & 3.29 & 11.9 & 15.4 & 4.70 & 4.65 & 0.06 & 1.12 & 2.82 \\
& Total & 56.2 & 30.5 & 5.30 & 22.3 & 18.4 & 5.68 & 6.16 & 0.07 & 1.15 & 2.83 \\
\hline
\end{tabular}

Unit: $n g \mathrm{~L}^{-1}$, S: soluble fraction, P: particulate fraction. Total: $\mathrm{S}+\mathrm{P}$.

of PAHs in the P-fraction increased with molecular weight. A similar tendency was observed in L-II and -III, although concentrations of PAHs were lower. The finding that the higher-molecular weight PAHs were mainly in the P-fraction is evidence that the PM in the snow originated from combustion.

\section{Inorganic Ions}

The chromatograms revealed $\mathrm{Na}^{+}, \mathrm{NH}_{4}^{+}, \mathrm{Ca}^{2+}, \mathrm{Cl}^{-}$, $\mathrm{NO}_{3}{ }^{-}$and $\mathrm{SO}_{4}{ }^{2-}$ as major inorganic ions and $\mathrm{K}^{+}, \mathrm{Mg}^{2+}$ and $\mathrm{F}^{-}$as minor ions in the three snow layers (Table 3). The concentrations were generally highest in L-I and lowest in L-III. The exceptions were $\mathrm{Cl}^{-}$, which was highest in L-II and $\mathrm{SO}_{4}{ }^{2-}$, which was lowest in L-II. Concentrations of $\mathrm{NH}_{4}{ }^{+}$ and $\mathrm{SO}_{4}{ }^{2-}$, which mainly originate from human activities such as fertilizers and combustion of organic matter, were very high in L-I, which suggests that L-I was contaminated with combustion gas. The concentration of $\mathrm{Na}^{+}$, a marker of sea salts, was highest in L-I. The concentration of $\mathrm{nssCa}^{2+}$, a marker of soil, which is calculated from the concentration of $\mathrm{Na}^{+}$in clean ocean, was highest in L-I, suggesting that L-I contained sea salts and soils such as Asian Dust. The very high concentration of $\mathrm{nssSO}_{4}{ }^{2-}$ in L-I provides further evidence of combustion $\mathrm{PM}$ in this layer.

\section{Back Trajectory Analysis}

It is not easy to define the dates of snowfall at the snow pit, because Murododaira is a remote isolated place covered with deep snow during winter season. We tried to estimate the dates by using records of weather, snowcap, and snowfall/depth of Mt. Tateyama from the Japan Meteorological Agency and the analytical results obtained above. The dates of snowfall for L-I and -II were estimated to be February 23-24 and March 15-21, 2015, respectively. 3 -day back trajectories of air massed during February 2324, 2015, passed through northeastern and central China, including deserts which tend to emit Asian Dust, and megacities which emit combustion PM and gas (Fig. 3(A)). During this period, an Asian Dust storm arrived at Toyama, supporting the idea that the dust storm was responsible for the high concentration of PM in L-I. We collected TSP samples on the Noto Peninsula from 2004 to 2014 and determined PAHs and NPAHs. The atmospheric PAH and NPAH concentrations increased during the period from midOctober to mid-April every year and the TSP concentration often increased in the period from late winter to early spring (Yang et al., 2007; Hayakawa et al., 2011; Tang et al., 2015). As a possible reason for the large ratio (89\%) of $\left[\mathrm{nssSO}_{4}{ }^{2-}\right] /\left[\mathrm{SO}_{4}{ }^{2-}\right]$ in L-I, the emission of volcanic gas near the snow pit might be considered (Watanabe et al., 2016). These observations explain why the concentrations of PAHs, $\mathrm{nssCa}^{2+}$ and $\mathrm{nsSSO}_{4}{ }^{2-}$ were high in L-I.

The back trajectories of air masses during March 15 and 18-20, 2015, came not from China but from the Yellow Sea, East China Sea and Sea of Japan. As a result, L-II contained sea salts but not combustion PM or gas (Fig. 3(B)). This is why the air masses of this period did not contain high concentrations of PAHs.

\section{Atmospheric Behavior of PAHs over the Sea of Japan}

A triple-nested two-dimensional dynamic cloud model demonstrated that in winter season, clouds form over the Sea of Japan 50-150 km leeward of the Asian continent and gradually develop in height and convective activity. Snow clouds strengthen around $30 \mathrm{~km}$ off the western coasts of Honshu and Hokkaido, Japan. The dominant precipitation is snow over the mountain area along the western coasts (Murakami et al., 1994), where $\mathrm{SO}_{4}{ }^{2-}$ and Asian Dust longrange transported from China were detected in the snow (Honoki et al., 2001; Osada et al., 2004; Watanabe et al., 2011). Snow clouds contain PM-associated PAHs and gasphase PAHs over the Sea of Japan according to this mechanism.

The solubility of PAHs in water increases with decreasing

Table 3. Concentrations of Inorganic Ions in the Snow.

\begin{tabular}{lllllllll}
\hline Layer & $\mathrm{Na}^{+}$ & $\mathrm{NH}^{4+}$ & $\mathrm{Ca}^{2+}$ & $\mathrm{nssCa}^{2+}$ & $\mathrm{Cl}^{-}$ & $\mathrm{NO}_{3}^{-}$ & $\mathrm{SO}_{4}^{2-}$ & $\mathrm{nssSO}_{4}^{2-}$ \\
\hline III & 0.24 & $<\mathrm{LOQ}$ & 0.12 & 0.11 & 0.19 & 0.07 & 0.18 & 0.16 \\
II & 0.32 & $<$ LOQ & 0.20 & 0.18 & 1.08 & 0.35 & 0.05 & 0.01 \\
I & 0.42 & 0.57 & 0.26 & 0.24 & 0.73 & 1.40 & 1.37 & 1.31 \\
\hline
\end{tabular}

Unit: $\mathrm{mg} \mathrm{L}^{-1}$ in S-fraction. < LOQ: detected but lower than quantification limit. 


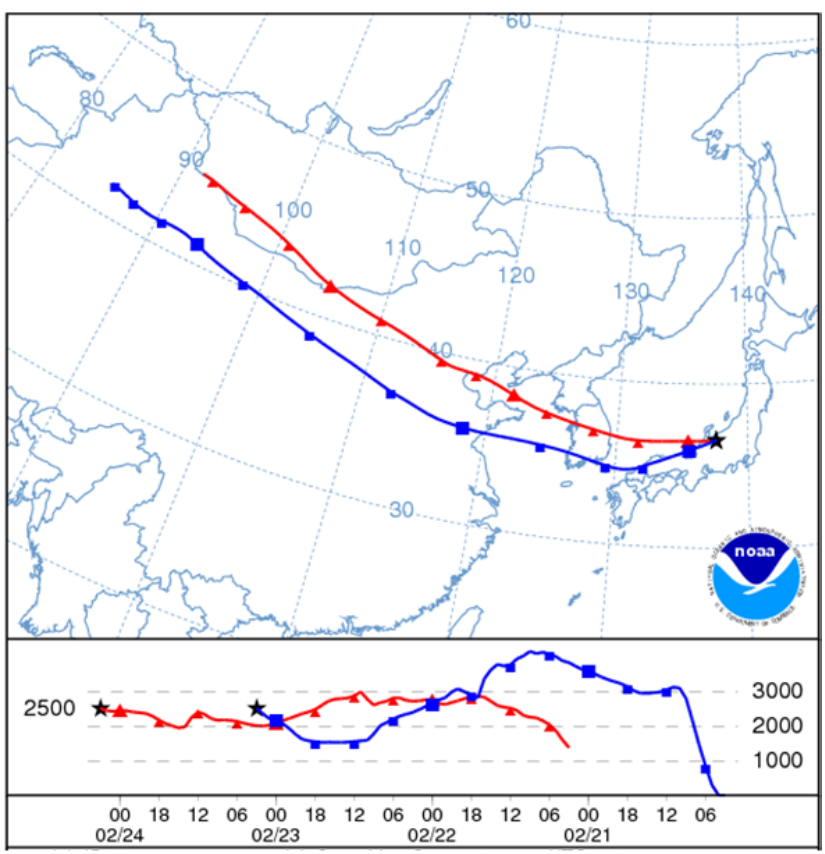

(A)

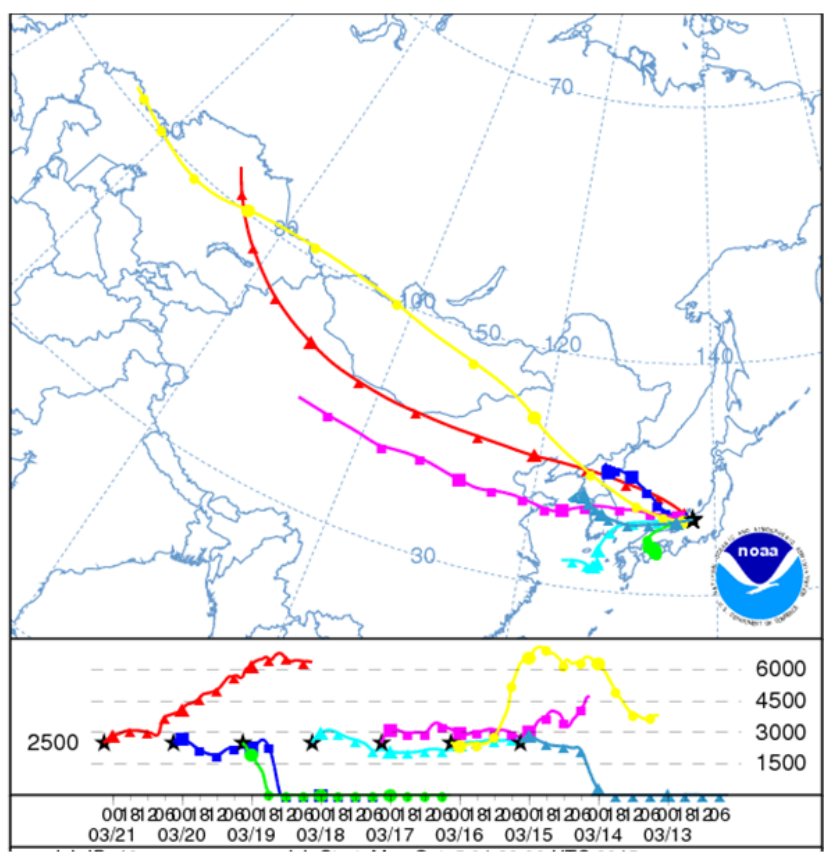

(B)

Fig. 3. Back Trajectory Analysis (A) February 23-24, 2015 (L-I); (B) March 15-21, 2015 (L-II).

molecular weight. The ratios (\%) of PAHs in the P-fraction to the total PAHs in the melted snow (closed circles in Fig. 4) decreased with the increase in octanol/water partition coefficient $\left(K_{\text {ow }}\right)$, where $K_{\text {ow }}$ of each PAH was obtained from the literature (Feng et al., 2007). On the other hand, semi-volatile PAHs are distributed between the PM and gas phases in the atmosphere. The percentage of PAHs in the gas phase increases with decreasing molecular weight. The percentages of PM-associated PAHs in the atmosphere were calculated from the literature (Araki et al., 2009) and are shown as open circles in Fig. 4. It is important to consider the distributions of PAHs not only in the atmosphere but also in snow and melted snow. PAHs with 6 rings, such as IDP and BghiPe, whose $K_{\mathrm{ow}}$ are 6.6 and 7.1, respectively, exist in the P-fraction in the filtrate of melted snow. However, for PAHs with 5 rings or fewer, such as $\mathrm{BaP}$ and Pyr, the percentages of PAHs in the P-fraction decreased as $K_{\text {ow }}$ decreased from 6.1 to 5.2. By contrast, in the atmosphere, not only 6- and 5-ring PAHs but also 4-ring PAHs (BaA and $\mathrm{Chr}$ ) with $K_{\mathrm{ow}}$ over 5.9 exist in the PM phase, but the percentages of PAHs in the PM phase were significantly smaller for the other 4-ring PAHs, such as Pyr and FR, whose $K_{\mathrm{ow}}$ values are both 5.2. There is a large difference in the distribution of 5-ring PAHs between the PM-phase in the atmosphere and the P-fraction in the filtrate of melted snow.

As a possible reason for this difference, the following behavior of PAHs may be considered:

$$
\begin{aligned}
& \mathrm{PAH}_{\mathrm{g}} \rightarrow \mathrm{PAH} \\
& \mathrm{PAH}_{\mathrm{p}} \rightarrow \mathrm{PAH}_{\mathrm{p}^{\prime}}+\mathrm{PAH}_{\mathrm{s}^{\prime}}
\end{aligned}
$$

where $\mathrm{p}$ and $\mathrm{g}$ are the PM and gas phases in the atmosphere, and ${ }_{\mathrm{p}^{\prime}}$ and $\mathrm{s}_{\mathrm{s}^{\prime}}$ are the $\mathrm{P}$ - and $\mathrm{S}$-fractions in the snow solution. As shown in Fig. 5, the gas-phase $\mathrm{PAH}\left(\mathrm{PAH}_{\mathrm{g}}\right)$ in the atmosphere is absorbed by the snow as PM-unassociated PAH $\left(\mathrm{PAH}_{\mathrm{s}}\right)($ Eq. (3)). The PM-associated PAH in the atmosphere $\left(\mathrm{PAH}_{\mathrm{p}}\right)$ is also absorbed by the falling snow. Then $\mathrm{PAH}_{\mathrm{p}}$ moves mainly into the P-fraction $\left(\mathrm{PAH}_{\mathrm{p}^{\prime}}\right)$ but partly into the $\mathrm{S}$-fraction $\left(\mathrm{PAH}_{\mathrm{s}^{\prime}}\right)$ in the case of PAHs with 5 rings or fewer (Eq. (4)). These results suggest that the gas-phase $\mathrm{PAH}$ in the atmosphere exists as the S-fraction in snow clouds, while PM-associated PAH exists as the Pfraction in snow clouds but dissociates partly to the Sfraction in the melted snow.

It is interesting that PAHs in the P-fraction were observed in all layers. At the time of snow sampling, L-III was collected as a blank snow, because this layer was uncolored. However, the concentrations of PAHs were higher in L-III than in L-II, suggesting that PAHs exist in the free atmosphere as background pollutants.

\section{CONCLUSIONS}

Three snow layers, L-I to -III, were collected from the wall of a snow pit, $6.36 \mathrm{~m}$ deep, at Murododaira on Mt. Tateyama, Japan. Each melted snow sample was separated into soluble $(\mathrm{S})$ and particulate $(\mathrm{P})$ fractions with a $0.5 \mu \mathrm{m}$ glass fiber filter. Ten PAHs, with 4-6 rings, and the inorganic ions were determined by the combined use of HPLC-FLD and IC.

The concentrations of PAHs were highest in L-I, in which almost all of the PAHs with 5-6 rings were in the P-fraction. A similar tendency was observed in L-II and -III, although the PAH concentrations were lower. Furthermore, $\mathrm{nssSO}_{4}{ }^{2-}$ existed only in the S-fraction. The air mass for L-I, traced via back trajectory, passed through northeastern and 


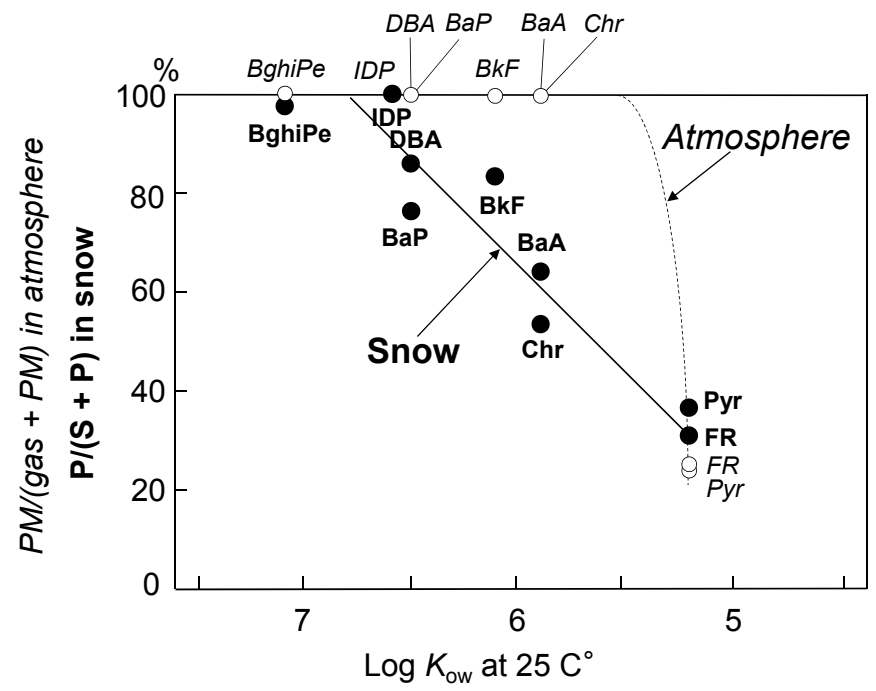

Fig. 4. Distribution of PAHs vs. Vapor Pressure. Vapor pressures ( $\mathrm{Pa}$ at $25^{\circ} \mathrm{C}$ ) of PAHs used were cited from the report by Feng et al. (2007).

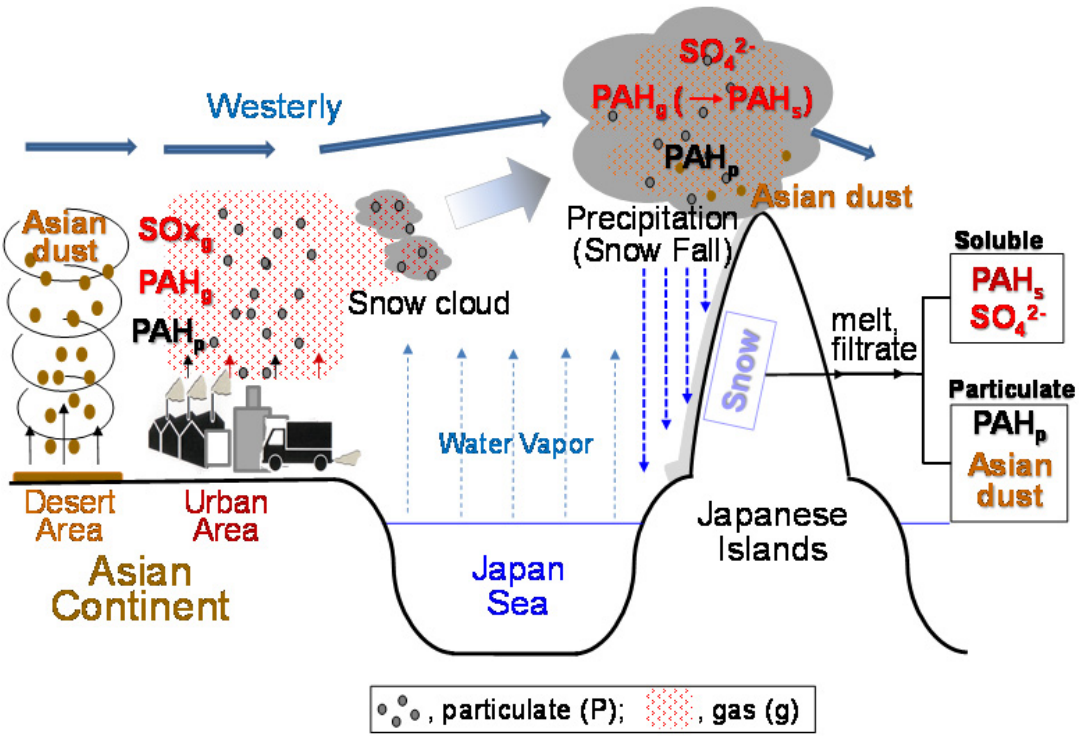

Fig. 5. Atmospheric Behavior of PAHs over the Japan Sea.

central China. These results indicated that PAHs, transported long-range from China to Japan, precipitated in snow on Mt. Tateyama.

\section{ACKNOWLEDGMENTS}

This research was supported in part by a Grant in Aid for Scientific Research (No. 21256001) and the Global Environment Research Fund (5-5106) from the Ministry of the Environment, Japan, and the Japan-New Zealand and Japan-Russia Joint Researches from the Japan Society for the Promotion of Science.

\section{REFERENCES}

Araki, Y., Tang, N., Ohno, M., Kameda, T., Toriba, A. and Hayakawa, K. (2009). Analysis of atmospheric polycyclic aromatic hydrocarbons and nitropolycyclic aromatic hydrocarbons in gas/particulate phases separately collected by a high-volume air sampler equipped with a column packed with XAD-4 resin. J. Health Sci. 55: 77-85.

Feng, J., Yang, Z., Niu, J. and Shen, Z. (2007). Remobilization of polycyclic aromatic hydrocarbons during the resuspention of Yangtze River sediment using a particle entrainment simulator. Environ. Pollut. 149: 193-200.

Hayakawa, K., Tang, N., Sato, K., Izaki, A., Tatematsu, M., Hama, H., Li, Y., Kameda, T. and Toriba, A. (2011). Development of HPLC determination method for trace levels of 1-, 2-nitropyrenes and 2-nitrofluoranthene in airborne particulates and its application to samples collected at Noto Peninsula. Asian J. Atmos. Environ. 5: 146-151.

Hayakawa, K., Tang, N. and Toriba, A. (2017). Recent 
analytical methods for atmospheric polycyclic aromatic hydrocarbons and their derivatives. Biomed. Chromatogr. 31: e3862.

Honoki, H., Tsushima, K. and Hayakawa, K. (2001). Inorganic constituents in snow accompanied by winter wind and their origin in the Hokuriku districts. J. Health Sci. 47: 559-564.

International Agency for Research on Cancer (2013). IARC: Outdoor air pollution a leading environmental cause of cancer deaths, http://www.iarc.fr/en/mediacenter/iarcnews/pdf/pr221.E.pdf, Last Access: 30 May 2017).

Iwasaka, Y., Yamamoto, M., Imasu, R. and Ono, A. (1988). Transport of Asian dust (KOSA) particles. Tellus 40B: 494-503.

Keene, W.C., Pszenny, A.A.P., Galloway, J.N. and Hawley, M.E. (1986). Sea-salt corrections and interpretation of constituent ratios in marine precipitation. J. Geophys. Res. 91: 6647-6658.

Murakami, M., Clark, T. and Hall, W. (1994). Numerical simulations of convective snow clouds over the Sea of Japan; Two-dimensional simulations of mixed layer development and convective snow cloud formation. Meteorol. Soc. Jpn. 72: 43-62.

Nishikawa, M., Kanamori, S., Kanamori, N. and Mizoguchi, T. (1991). Kosa aerosol as eolian carrier of anthropogenic materials. Sci. Total Environ. 107: 13-27.

Osada, K., Kido, M., Iida, H., Yabuki, H., Kohjima, S., Kawada, K. amd Nakawo, M. (2000). Chemical stratigraphy of water soluble constituents in spring snow cover at Murododaira, Tateyama Mts., Japan. Seppyou 62: 3-13 (in Japanese).

Osada, K., Iida, H., Kido, M., Matsunaga, K. and Iwasaka, Y. (2004). Mineral dust layers in snow at Mount Tateyama, central Japan: Formation processes and characteristics. Tellus 56B: 382-392.

Saarnio, K., Sillanpää, M., Hillamo, R., Sandell, E., Pennanen, A. and Salonen R. (2008). Polycyclic aromatic hydrocarbons in size-segregated particle matter from six urban site in Europe. Atmos. Environ. 42: 9087-9097.

Tang, N., Hakamata, K., Sato, K., Okada, Y., Yang, X., Tatematsu, M., Toriba, A., Kameda, T. and Hayakawa,
K. (2015). Atmospheric behaviors of polycyclic aromatic hydrocarbons at a Japanese remote background site, Noto peninshula, from 2004 to 2014. Atmos. Environ. 120: 144-151.

Tang, N., Suzuki, G., H. Morisaki, H., Tokuda, T., Yang, X., Zhao, L., Lin, J., Kameda, T., Toriba, A. and Hayakawa, K. (2017). Atmospheric behaviors of particulate-bound polycyclic aromatic hydrocarbons and nitropolycyclic aromatic hydrocarbons in Beijing, China from 2004 to 2010. Atmos. Environ. 152: 354-361.

Watanabe, K., Saito, Y., Tamura, S., Sakai, Y., Eda, N., Aoki, M., Kawabuchi, M., Yanada, H., Iwai, A. and Kawada, K. (2005). Chemical characteristics of the snow pits at Murododaira, Mount Tateyama, Japan. Anal. Gracio. 52: 102-110.

Watanabe, K., Nishimoto, D., Ishita, S., Eda, N., Uehara, N., Uehara, Y., Takahashi, G., Kunori, N., Kawakami, T., Shimada, W., Aoki, K. and Kawada, K. (2011). Formaldehyde and hydrogen peroxide concentrations in the snow cover at Murododaira, Mt. Tateyama, Japan. Bull. Glaciol. Res. 30: 33-40.

Watanabe, K., Cao, R., Naruse, I., Ishita, S., Uehara, Y. and Honoki, H. (2013). Measurement of sulfate particulates using a sulfate monitor at plain site and a mountainous site in Toyama. Earozoru Kenkyu 28: 140149 (in Japanese).

Watanabe, K., Hirai, T., Nakagawa, K., Ogawa, K., Uehara, Y., Honoki, H., Shimada, W., Aoki, K. and Kawada, K. (2016). On the influence of fumarolic activity at Murododaira volcano on snow chemistry at Murododaira, Mt. Tateyama. Seppyo 78: 307-315 (in Japanese).

Yang, X.Y., Okada, Y., Tang, N., Matsunaga, S., Tamura, K., Lin, J.M., Kameda, T., Toriba, A. and Hayakawa, K. (2007). Long-range transportation of polycyclic aromatic hydrocarbons from China to Japan. Atmos. Environ. 41: 2710-2718

Received for review, May 2, 2018 Revised, September 30, 2018 Accepted, October 9, 2018 